\title{
Keeping well, teaching well: supporting staff wellbeing
}

\section{Katy Savage}

University of Strathclyde, UK

Sean Morrissey

University of Strathclyde, UK

Keywords: Covid-19; teacher wellbeing; education development; staff CPD.

\section{The challenge}

As an education development team, our initial responses to supporting staff in the pandemic were inevitably and completely focused on supporting staff in the pivot to online and blended learning. However, as time went on and there were no signs of 'normality' returning our 'read' of staff needs and requirements began to change. We saw staff wellbeing emerge as a need that was increasingly important to address.

Staff were speaking to us openly about feeling and experiencing symptoms of stress, working increasing hours to keep up with their workload, having less time to focus on family, and the difficulties of keeping themselves well in an effort to 'keep up'. They were telling us that many of the work challenges they were experiencing during the pandemic were contributing to stress, discomfort, and exhaustion. What they described were signs of the 'exhaustion funnel', a concept developed by Asberg that is explored by Williams and Penman (2011, p.212) and shown below in Figure 1.

Figure 1. The exhaustion funnel (Williams and Penman, 2011).

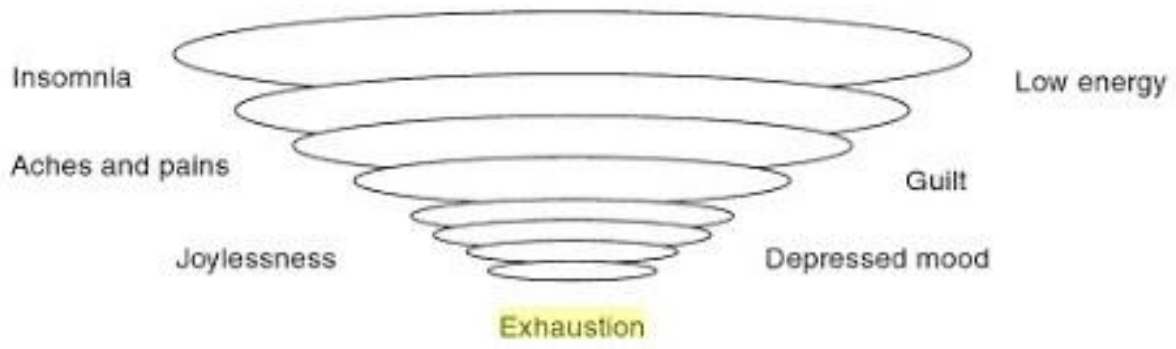


The authors note that as we get busier, we let go of what nourishes and energises us in favour of what seems to be important. As stressors increase, we let go of more and more, so that as we funnel down to exhaustion, all that remains are stressors. This model of exhaustion and professional burnout needs to be read in the light of recent research findings about the positive links between teacher attrition and burnout (Madigan and Kim, 2021). This research highlights a key risk to teacher performance and underlines that teacher wellbeing needs to be supported and protected.

In terms of institutional context, staff wellbeing was a clear priority and a number of institutional supports were in place such as a Wellbeing Hub and non-working Friday Rest Days during lockdown (now meeting-free Fridays). While institutional and some wider supports (Hughes, 2020) were available to support student wellbeing, the education development team saw teacher wellbeing as an institutional and sector priority that needed and deserved attention.

\section{The response}

\section{Teachers' Lounge}

Our initial response to noticing the need for staff wellbeing support was to introduce a weekly Teachers' Lounge. This was a space for staff to come along and enjoy a cup of coffee and a chat. It built on our growing expertise in developing Peer Networks as a means of supporting staff (Savage et al., 2021). Our vision was to support staff by creating a space for them to come together informally with like-minded peers to identify and take responsibility for their developmental needs and plan how these might be addressed. Evaluation through informal dialogue with staff revealed that this strategy was successful in creating a safe and supportive space for staff. In fact, one regular participant recently told me: 'that one half hour in the week was sometimes the only thing that kept me hanging on and got me through'.

\section{Keeping well, teaching well}

Driven to build on the existing success of the Teachers' Lounge and armed with the developmental needs staff told us about in the Teachers' Lounge, we set to create a more specific and targeted programme to address the wellbeing needs of staff involved in 
learning and teaching. Our institution does not have a specific 'wellbeing team' for staff and the message from our executive team is that wellbeing is everyone's responsibility. The first iteration of this programme explored topics either directly related to wellbeing or to a teaching style that can be introduced or re-imagined to support wellbeing, see Table 1 below.

Table 1. Staff CPD Programme: Keeping well, teaching well.

\begin{tabular}{|c|c|c|}
\hline \multicolumn{3}{|c|}{ Staff CPD Programme: Keeping well, teaching well } \\
\hline Topics & Format & Time \\
\hline $\begin{array}{l}\text { Wu Wei Teaching (Reis, } \\
\text { 2021) (the art of allowing } \\
\text { students space online to } \\
\text { learn), Assessment and } \\
\text { Feedback, Physical } \\
\text { Activity, Boundaries in } \\
\text { Learning and Teaching, } \\
\text { Mental Health, and } \\
\text { Mindfulness in Learning } \\
\text { and Teaching. }\end{array}$ & $\begin{array}{l}\text { Short input at outset and } \\
\text { then explored how that } \\
\text { topic or teaching style can } \\
\text { be put into practice or re- } \\
\text { worked to enhance } \\
\text { wellbeing. }\end{array}$ & $\begin{array}{l}\text { Ten-week block of weekly } \\
1.5 \mathrm{~h} \text { sessions. }\end{array}$ \\
\hline
\end{tabular}

Participant evaluations showed how well received this series was and we achieved our aim of reaching beyond those participants who routinely attend education development sessions. Approximately 20 staff attended each session and comments from participants included:

- ' [I liked the emphasis on] the importance of taking care of myself to deal with stress and anxiety. Liked prioritisation of the breath and movement activities to counter our ways of working'.

- 'Some useful tips for balancing work/life, and a couple of techniques which I could use with students'.

Our second ten-week iteration of this programme is still in progress: see Table 2 below. 
Table 2. Staff CPD Programme: Staying well, teaching well.

\begin{tabular}{|l|l|l|}
\hline \multicolumn{2}{|l|}{ Staff CPD Programme: Staying well, teaching well } \\
\hline Topics & Format & Time \\
\hline Topics from spring & As above with the & Ten-week block of weekly \\
programme, plus Qi & addition of 'Try something & 1.5h sessions. \\
Gong, Guided meditation, & new' sessions to find new & \\
and Mindfulness and & and helpful ways of & \\
Creativity with a local & supporting their wellbeing. & \\
artist. & \\
Plus Digital wellbeing, i.e., & \\
'top tech tips to improve & \\
your teaching and support & \\
your wellbeing'. & \\
Two final open sessions & \\
titled 'From Keeping well & & \\
to Staying well' to & & \\
encourage staff to & \\
consider how to maintain \\
their wellbeing in the \\
longer term.
\end{tabular}

\section{Recommendations}

For an education development team, there was some risk associated with focusing on wellbeing. However, we gained institutional support and the response from staff (through evaluations and conversations we have had with them) has confirmed and validated that this programme was timely and supportive.

Our learning from this programme leads us to recommend the following to others considering similar approaches: 
- Teacher attrition is positively linked to burnout and so teacher wellbeing is important, and staff need and deserve the opportunity to discuss this openly and directly within a supportive and solution-focused space.

- Staff need safe and supportive spaces to discuss and develop responses to challenges they experience.

- Offering staff opportunities to experience a variety of ways to support wellbeing is helpful; staff were willing to 'try something new' and were positive about incorporating new techniques into future wellbeing plans.

- In discussing their own wellbeing and practices to support wellbeing, learning and teaching staff apply their learning to the classroom and use what they have learned to support student wellbeing, supporting a whole university wellbeing approach.

- Informal discussion time is important. Part of the success of these sessions is around the way they were structured: short developmental input, followed by a larger portion of time to discuss as a whole group or in small breakout groups how the learning can be implemented to support wellbeing.

\section{References}

Hughes, G. (2020) Be well, learn well. $1^{\text {st }}$ edn. London: Red Globe Press.

Madigan, D. and Kim, L. (2021) 'Towards an understanding of teacher attrition: a metaanalysis of burnout, job satisfaction, and teachers' intentions to quit', Teaching and Teacher Education, 105, p.103425. https://doi.org/10.1016/j.tate.2021.103425.

Reis, C. (2021) Wu Wei Video - Connect @ XJTLU. [online] Connect.xjtlu.edu.cn. Available at: https://connect.xjtlu.edu.cn/view/view.php?t=J7ojECfKBelrwhgxzPcX (Accessed: 31 August 2021).

Savage, K., Morrissey, S., Willison, D., Guccione, K. and Zike, J. (2021) Peer Support Networks: Fostering a sense of belonging. Available at: https://strath.pagetiger.com/PSN/tools (Accessed: 11 June 2021).

Williams, M. G. and Penman, D. (2011) Mindfulness: the eight-week meditation programme for a frantic world. London: Hachette Digital. 


\section{Author details}

Katy Savage is the Academic Director and Development Lead for Learning and Teaching at Strathclyde University. Katy's overarching goal as a practitioner is to improve student learning through supporting academic professional learning and teaching staff to have confidence, be bold and innovative in their approaches, to find their voice, and to realise their leadership potential. Katy's key interests lie in the use of staff peer networks to support academic development, course and class design, and leadership in learning and teaching.

Sean Morrissey has a PhD in Sociology and a Master of Research (MRes) from the University of Aberdeen. He leads Strathclyde's PGCert, Learning and Teaching in Higher Education Programme and his research interests include digital capabilities, peer support networks, and pedagogy and practice in online/blended learning. 